\title{
Reliability of Agricultural Tractors According to Polish Farmers
}

\author{
Karol DURCZAK
}

\begin{abstract}
The progressing digitisation of European and global agriculture requires a rational approach to the reliability of agricultural machinery and vehicles. It is not easy to access data on failures of their parts, units and systems, which are necessary for classic characterisation of reliability. For this reason, it is necessary to develop other unconventional methods of acquiring information about the technical condition of machinery and convert it into a numerical form. This study presents an original method of quantifying the relative index of reliability of farm tractors based on their owners' subjective opinions. At present the rankings obtained by means of this method are the only tool supporting purchase decisions in situations of uncertainty and risk. Polish farmers found Valtra tractors to be the most reliable. The average reliability index is 0.87 . Among 12 brands in the ranking the users rated 11 specific reliability criteria of Valtra tractors the highest. The runner-up was John Deere-a global manufacturer of agricultural machinery and vehicles. The German brand Fendt was the third in the ranking.
\end{abstract}

Keywords: decision-making; expert system; farm tractors; rankings; reliability

\section{INTRODUCTION}

Reliability, quality and price are basic advertising and marketing slogans. High, excellent or perfect reliability is supposed to make potential customers interested in a product and encourage them to purchase it. In quality management agricultural machinery and vehicles are defined as products, although they also provide services. Apart from that, they also use two other forms of the product, i.e. processed material (e.g. fuel, oils and lubricants) as well as human intellectual product (e.g. software for controllers, computers and satellite navigation, service plan, instruction manual and driving licence).

It is tautology to use the terms quality and reliability alternatively as synonyms. According to ISO 9000: 2015: Quality Management Systems-Fundamentals and Vocabulary, quality is defined as a set of inherent features, which include reliability. Like functionality, ergonomics, safety of use and design, reliability is an inseparable and inherent feature of a specific technical facility, which begins as early as the stages of design, construction and production.

Reliability, which is an important property of agricultural machinery and vehicles, is defined very briefly and descriptively in the manuscript as the ability of a technical facility not to fail. As it is understood as the probability of occurrence of a failure within a particular period of time $R(t)$, it requires specific numerical data to be quantified. Neither manufacturers nor service centres disclose this sensitive and confidential information. The lack of service history with information about failures of a technical facility also makes it impossible to determine other important reliability functions such as failure intensity $\lambda(t)$, frequency $f(t)$ and unreliability $F(t)$.

When machinery and vehicles are retrofitted with additional modules, like in the automotive industry, their reliability and the reliability of the systems they form is usually reduced. Although the parallel system of connections (relations) is more desirable, the serial system is used because these modules have different functions in the machine, which are independent of each other. However, there is some ambivalence here. New systems are installed to inform of unexpected failures or even to prevent them. Therefore, it is recommended to conduct research to confirm this hypothesis.

It is impossible to avoid the progressing automation and computerisation of field works. We can say that agricultural machinery that is currently manufactured has already entered the fourth industrial revolution (because of Agriculture 4.0), which involves the digitisation of agriculture. The previous revolution, referred to as 'Precision Agriculture', made agriculture one of the world's most advanced sectors in terms of the use of telemetry, GPS, electrohydraulic technologies and linear modelling $[1,2]$. Now it is time for the Digital Revolution, in which farmers' decisions are based not only on their experience, but also on reliable information.

According to agricultural machinery manufacturers, precision farming and site-specific farming will be trends in the development of agriculture. So far, manufacturers have been concentrating on the production of bigger and bigger and more and more efficient agricultural machinery. In the future, they plan to develop modular systems consisting of many working units that will optimally grow, protect and fertilise crops when plants need it.

As machines will constantly communicate with each other in Agriculture 4.0, it is necessary to provide stable access to the Internet in rural areas to develop these technologies in Europe. At the moment this problem is one of the biggest barriers to the development of this system.

When we started implementing the IFOP project (Independent Farmers' Opinion Poll) in 2017, we assumed that all parts of Poland had stable access to the Internet. IFOP is a web portal where users of agricultural machinery and vehicles (currently these are users of tractors, loaders, mowers and combine harvesters) share their own experiences voluntarily, indirectly and not necessarily personally. Their subjective opinions about several dozen different characteristics of these technical facilities are not published directly. According to the methodology prepared and adopted at the Institute of Biosystems Engineering, Poznań University of Life Sciences, Poland, data acquired from users are first verified and repaired, and only then they are statistically processed and published [3, 4].

The IFOP portal is not another public Internet forum, where users only express their opinions. Although subjective judgments may be extreme, they become 
averaged in a large random sample, and thus greater objectivity and intellectual honesty are guaranteed. Among the inherent features that are relevant to the global quality of machinery, we can find those that are decisive to durability and reliability. It is necessary to apply the methodology that will enable quantification of the reliability of technical facilities according to their owners' ratings, who should ideally be long-term users.

The author has already published a method of valuation of the reliability of farm tractors based on failures found a posteriori [5]. The abstract model obtained by deduction has the form of an algebraic formula based on the Defects per Opportunity indicator, DPO. It enables the calculation of model times of failure-free operation of a specific population of renewable products. The original method is universal and it can be used successfully for all groups of agricultural machinery after adaptation, i.e. when the specific construction of machines is taken into account at the stage of decomposition. The effect is the probability that the object under analysis will not fail, regardless of the number and type of assembly groups. The ex-ante evaluation assumes that these groups have a series structure. Apart from that, it does not require prior estimation of the distributions of theoretical failures, which can be used only when at least one parameter is known [6].

If we assume only the simplified two-state process of agricultural machinery operation, which is consistent with the classical theory of reliability [7], the problem of acquiring reliable data about failures of individual systems and parts still needs to be solved.

The classical theory of reliability has good theoretical background. However, a full service history with detailed data of the occurrence of a failure (e.g. time, day, month, year) is necessary to calculate basic characteristics of technical facilities. Only then we can calculate the functional values and present them in a diagram or ranking (according to the expectations of anyone interested in purchasing, servicing, production or trade), like in a car ranking. This study proposes a different approach to this problem, based on tools and methods used in marketing research and psychology. It is necessary to give questionnaire surveys to regular and experienced users of these machines, who also know the characteristics of similar models of other brands.

The aim of the study was to develop an original method of quantifying the reliability of agricultural machinery and vehicles based on their users' individual opinions. The study was conducted on tractors, which, according to statistics, can be found on each modern farm.

\section{METHOD}

Even if the reliability of technical facilities is described with functional and numerical characteristics, it is still an unmeasurable, qualitative trait in the metrological sense. Therefore, instead of giving the number and time of failures, which are difficult to determine (not everyone records the service history), psychological associations were used. In this study it was the process of automatic association of a given tractor unit with a five-degree ordering scale of ratings. The scale reflected the respondents' subjective opinions about the reliability of individual elements of the construction of a tractor, where:
1 - very low rating,

2 - low rating,

3 - average rating,

4 - high rating,

5 - very high rating.

This approach eliminates the problem of definite detection of a failure, which in the classical theory of reliability is interpreted as the transition from the condition of technical usability to being unusable [8-10]. This transition is not definite if we consider the use of agricultural machinery and vehicles, where the time is continuous and the states are discreet. The author has already considered the introduction of a four-state stochastic model of reliability of agricultural machinery and vehicles based on semi-Markov processes [11].

Among 51 quality-relevant traits of farm tractors, as many as 11 refer to reliability: engine power supply $\left(R_{1}\right)$ and cooling systems $\left(R_{2}\right)$, electric system $\left(R_{3}\right)$, drive system $\left(R_{4}\right)$, brake system $\left(R_{6}\right)$, hydraulic system $\left(R_{7}\right)$ and steering system $\left(R_{8}\right)$, gearbox $\left(R_{5}\right)$, PTO shaft $\left(R_{9}\right)$, three-point linkage $\left(R_{10}\right)$ and reliability of all connections $\left(R_{11}\right)$. The procedure of creation of the set of reliability traits $R_{i}$ was considerably simplified, because an average farm tractor has as many as 4000 repairable and unrepairable parts, which may become completely damaged in a random manner. Fig. 1 shows the algorithm which was used to determine the total index of reliability of a group of similar machines and vehicles (brand, model, type of use, year of manufacture, etc.).

\begin{tabular}{|c|c|}
\hline $\begin{array}{c}\text { Selection of set of inherent traits } \\
\text { for Reliability }(R) \text { criterion }\end{array}$ & $\begin{array}{c}\text { Stage } 4 \\
\text { Calculation of } \\
\text { reliabilityindicators } W_{R} \\
\text { and } W_{R}(\%)\end{array}$ \\
EXPERTS & $\begin{array}{c}\text { Stage 3 } \\
\text { SYSTEM MODERATOR }\end{array}$ \\
\hline $\begin{array}{c}\text { Rating }\left(R_{i}\right) \text { of detailed traits in } \\
\text { SFOP system with 5-degree } \\
\text { ordering scale } \\
\text { USERS }\end{array}$ & $\begin{array}{c}\text { Data verification and repair, } \\
\text { identification of errors and } \\
\text { verification of stochastic } \\
\text { independence of size of sets } \\
\text { ranked }\end{array}$ \\
SYSTEM ADMINISTRATOR \\
\hline
\end{tabular}

Figure $1 \mathrm{~A}$ universal algorithm used for the calculation of the reliability indicator of technical facilities $W_{R}(\%)$

This is an algorithmic-heuristic method, which can be classified as a multiple-criteria decision analysis (MCDA) system used in a situation of uncertainty and risk [12-15]. It develops operational research, which is valuable to practice $[16,17]$.

Experts' knowledge and experience are used to specify a set of reliability traits $\left(R_{i}\right)$ that are decisive to failure-free operation of a particular technical facility. Next, respondents use the IFOP Internet system www.nbor.pl to post their subjective opinions in 11 detailed categories and rate the reliability of technical facilities with a five-degree scale, without the need to provide the number of failures that occurred in a particular period of time. The questionnaires are sent online, verified and repaired if necessary.

Special software was developed to examine the entire volume of data acquired during their flow from the web portal to the database. The system was built using modern extract, transform, load (ETL) technologies, which the 
largest corporations and financial institutions (e.g. banks) use for operations on data. Such systems make it possible to acquire, process and format very large datasets so that they can be used as a reliable and classified source of information in analytical databases.

At this stage the significance of the stochastic number of datasets (users' opinions sent online) was also verified by means of a chi-squared test. Sets of category units (tractor brands) with the smallest number up to $\chi^{2}<\chi_{\alpha ; k-1}^{2}$ were selected, where: $\alpha$ - the significance level, $k-1$ the number of degrees of freedom, $k$ - the number of units in a category).

The reliability index $W_{R}$ is the simple arithmetic mean of users' ratings, which assumes values between 1.00 and 5. The closer a technical facility is to the maximum value, i.e. 5 , the higher its reliability is. On the other hand, $W_{R}=$ 1 means $100 \%$ failure rate and zero reliability. This is a purely theoretical value, as it requires all users to rate all of the 11 detailed criteria at the lowest level, i.e. 1.

Instead of the geometric mean, which seems to be natural due to the serial system known from the reliability theory, the arithmetic mean was used, because it averages opinions, especially extreme ones. The author followed the rational principles 'Trust the crowd' and 'Wisdom of the crowd', according to which the best solutions come from a large number of participants (users of a particular product), as they can be later averaged.

All the criteria were equally important, which simplified reality. Too many criteria (11 in our study) make it impossible, e.g. to use Saaty's pairwise comparisons PC [18]. This method precisely determines the weighting factors of criteria and indicates the response inconsistency ratio (IR), provided that the number of criteria does not exceed the limit of 9 elements, according to Miller's law $7 \pm 2[19]$

At the last stage the mean value is converted to a relative state, which allows for the maximum and minimum values of the $W_{R}$ index:

$$
W_{R}(\%)=\frac{W_{R}-W_{R(\min )}}{W_{R(\max )}-W_{R(\min )}}
$$

As $W_{R(\min )}=1$ and $\mathrm{W}_{R(\max )}=5$, the interval between the ratings is 4, and dependency Eq. (1) assumes a linear form, which is easy to implement:

$$
W_{R}(\%)=0.25\left(W_{R}-1\right)
$$

Thus, this simplified method (because it does not require the knowledge of a detailed repair history of each tractor) can be used to obtain the reliability index value within the range of $0-1$, like in the classical method. Relative values of the reliability index can be used to make rankings, which are valuable for practice.

\section{RESULTS}

The method was verified with data from the IFOP web portal, which were acquired from 1,350 users of farm tractors in Poland between March 2017 and February 2019. The age structure of the tractors was as follows (Fig. 2).

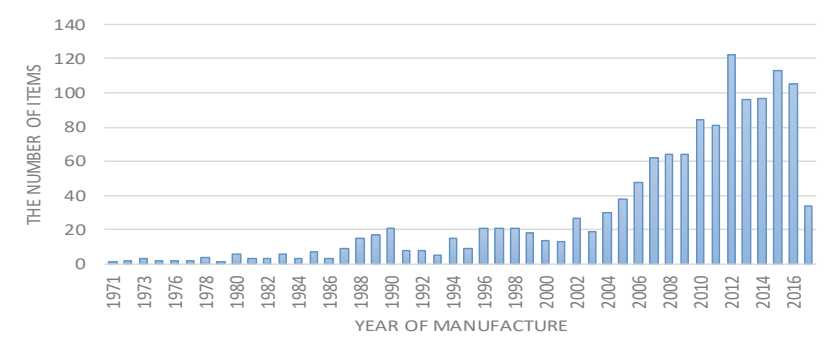

Figure $2 \mathrm{~A}$ histogram of the number of tractors rated vs the year of manufacture

There were mostly new vehicles rated. As much as $77 \%$ of the surveyed population was produced after Poland's accession to the EU (i.e. after May 2004). They are not older than 15 years and they are well-equipped with modern mechatronic systems which support the driveroperator and make their work safer. Therefore, they are within the time ranges of the normative use of tractors. The estimated life of tractors used on Polish farms is 20 years, with 12000 hours of normative use in this period, i.e. about $600 \mathrm{~h}$ a year. By comparison, in Switzerland the depreciation period is only 12 years (method developed by FAT Tänikon, currently AgroscopeReckenholz-Tänikon), and the normative use of $10000 \mathrm{~h}[20,21]$. However, the estimated annual use of tractors is the same as in Poland, i.e. $600 \mathrm{~h}$, regardless of the number of drive wheels and engine power.

The failure rate of slightly older tractors, i.e. those which were manufactured not earlier than 1987, will also be analysed, because they exceeded the limit of a large statistical sample (30 items). The results of the analysis of older tractors would not be reliable, as can be seen in the histogram.

Additionally, the ETL software for data quality management enabled the location and elimination of irregularities. Erroneous records made about $12 \%$ of the total number, so the database was reduced to 1193 records.

Tab. 1 shows an example of the relative reliability index $W_{R}(\%)$ calculated for one year.

\begin{tabular}{|c|c|c|c|c|c|c|c|c|c|c|c|c|c|c|c|}
\hline No. & Brand & Model & $R_{1}$ & $R_{2}$ & $R_{3}$ & $R_{4}$ & $R_{5}$ & $R_{6}$ & $R_{7}$ & $R_{8}$ & $R_{9}$ & $R_{10}$ & $R_{11}$ & $W_{R}$ & $W_{R}(\%)$ \\
\hline 1. & John Deere & $6215 \mathrm{R}$ & 4 & 5 & 5 & 5 & 5 & 4 & 3 & 5 & 4 & 4 & 4 & \multirow{7}{*}{4.36} & \multirow{7}{*}{0.84} \\
\hline 2. & Steyr & 6125 Profi & 5 & 5 & 5 & 5 & 5 & 5 & 5 & 5 & 4 & 5 & 5 & & \\
\hline 3. & Claas & 950 & 4 & 4 & 4 & 4 & 4 & 5 & 5 & 5 & 5 & 4 & 4 & & \\
\hline$\ldots$ & $\ldots$ & $\ldots$ & $\ldots$ & $\ldots$ & $\ldots$ & $\ldots$ & $\ldots$ & $\ldots$ & $\ldots$ & $\ldots$ & $\ldots$ & $\ldots$ & $\ldots$ & & \\
\hline 103. & Case IH & Farmall 85A & 4 & 4 & 4 & 4 & 4 & 4 & 4 & 4 & 4 & 3 & 2 & & \\
\hline 104. & New Holland & T6 & 1 & 2 & 2 & 3 & 2 & 3 & 1 & 3 & 2 & 3 & 1 & & \\
\hline 105. & Kubota & M115GX & 5 & 5 & 5 & 5 & 5 & 5 & 5 & 5 & 5 & 5 & 5 & & \\
\hline
\end{tabular}

Table 1 The data and method of calculation of the $W_{R}(\%)$ index for tractors manufactured in 2016 
The years 1992, 1993 and 2000 were eliminated because the respondents rated fewer than 30 tractors manufactured in those years. The reliability index value is shown in Fig. 3.

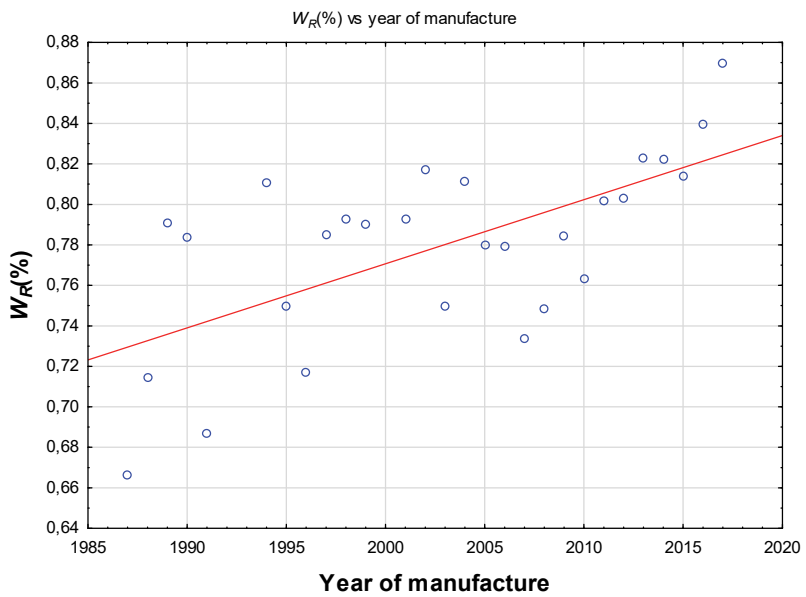

Figure 3 The relative index of reliability of farm tractors manufactured in the last 30 years $(r=0.6364, p=0.003)$
Users could see steady improvement in the reliability of their tractors. The oldest tractors, i.e. those made in 1987 , were considered the most unreliable $W_{R}(\%)=0.67$, whereas the newest ones, i.e. those manufactured in 2017, had the best ratings in all of the 11 reliability categories $W_{R}(\%)=0.87$. This means that the reliability of farm tractors increased by as much as $30 \%$ over the period of 30 years. This fact gives positive reputation to the construction and design offices where this technical equipment was manufactured. The users saw and appreciated the fact that the manufacturers modernised their models on a regular basis.

The $\chi^{2}$ test, which was used to verify this hypothesis at a significance level $\alpha=0.01$, did not show significant differences in the number of ratings for individual brands. As the result of the $\chi^{2}$ test was smaller than the table value $\chi_{0.01,11}^{2}$, there was no reason to reject the null hypothesis that the differences in the number of mowers were insignificant. This means that all the brands that exceeded the limit of 30 ratings could be ranked.

Tab. 2 shows an example of the relative reliability index $W_{R}(\%)$ calculated for one of the brands.

Table 2 The data and method of calculation of the $W_{R}(\%)$ index for the John Deere brand

\begin{tabular}{|c|c|c|c|c|c|c|c|c|c|c|c|c|c|c|c|c|}
\hline No. & Model & $\begin{array}{c}\text { Year of } \\
\text { manufacture }\end{array}$ & $\begin{array}{c}\text { Year of } \\
\text { purchase }\end{array}$ & $R_{1}$ & $R_{2}$ & $R_{3}$ & $R_{4}$ & $R_{5}$ & $R_{6}$ & $R_{7}$ & $R_{8}$ & $R_{9}$ & $R_{10}$ & $R_{11}$ & $W_{R}$ & $W_{R}(\%)$ \\
\hline 1. & $6125 \mathrm{M}$ & 2013 & 2014 & 4 & 3 & 4 & 5 & 4 & 4 & 4 & 4 & 5 & 5 & 4 & \multirow{7}{*}{4.42} & \multirow{7}{*}{0.86} \\
\hline 2. & $6220 \mathrm{SE}$ & 2001 & 2001 & 4 & 3 & 4 & 5 & 5 & 5 & 5 & 5 & 4 & 5 & 4 & & \\
\hline 3. & 6330 & 2010 & 2010 & 1 & 1 & 2 & 1 & 2 & 1 & 2 & 1 & 2 & 2 & 1 & & \\
\hline$\ldots$ & $\ldots$ & $\ldots$ & $\ldots$ & $\ldots$ & $\ldots$ & $\ldots$ & $\ldots$ & $\ldots$ & $\ldots$ & $\ldots$ & $\ldots$ & $\ldots$ & $\ldots$ & $\ldots$ & & \\
\hline 210. & $6220 \mathrm{SE}$ & 2007 & 2008 & 4 & 5 & 5 & 5 & 3 & 3 & 2 & 5 & 5 & 5 & 5 & & \\
\hline 211. & 5080 & 2011 & 2011 & 3 & 4 & 4 & 4 & 2 & 4 & 4 & 4 & 4 & 4 & 4 & & \\
\hline 212. & 6300 & 1994 & 2013 & 4 & 4 & 4 & 5 & 5 & 5 & 4 & 5 & 5 & 5 & 4 & & \\
\hline
\end{tabular}

The Tableau Public program was used in this study to generate and visualise reports, because it enables quick simulation research. It reports only the data that exceeded the limit of a large random sample. The available options (on the right) enable limitation of the results to the significant criterion only, i.e. reliability. In order to do so, the other main criteria such as functionality, ergonomics and design must be zeroed (Fig. 4).

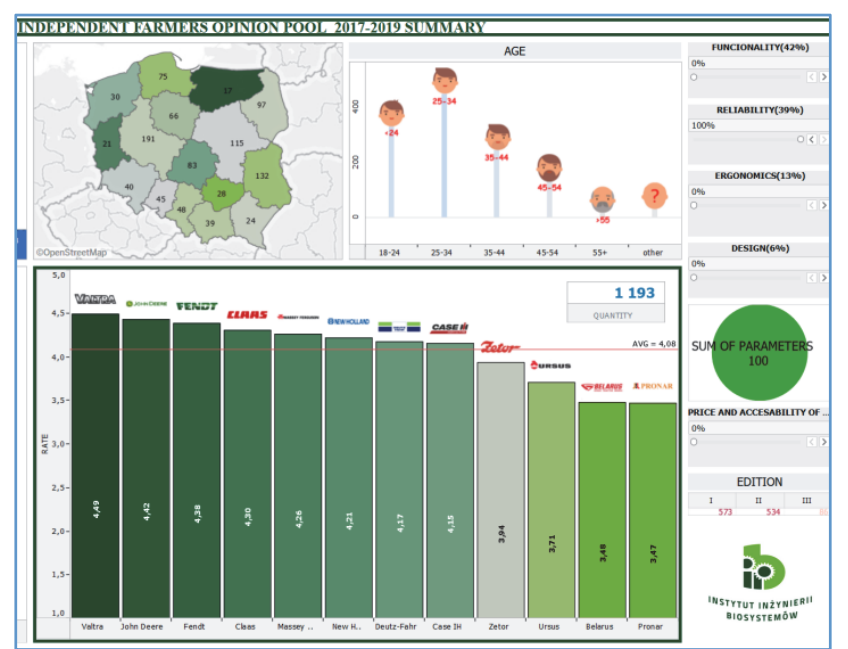

Figure 4 Tractor brands ranked according to the reliability index $W_{R}$ and the average value of the index for the total number of tractors
The results shown above were used to rank tractors according to the relative reliability index $W_{R}(\%)$ according to dependency 2 (Fig. 5).

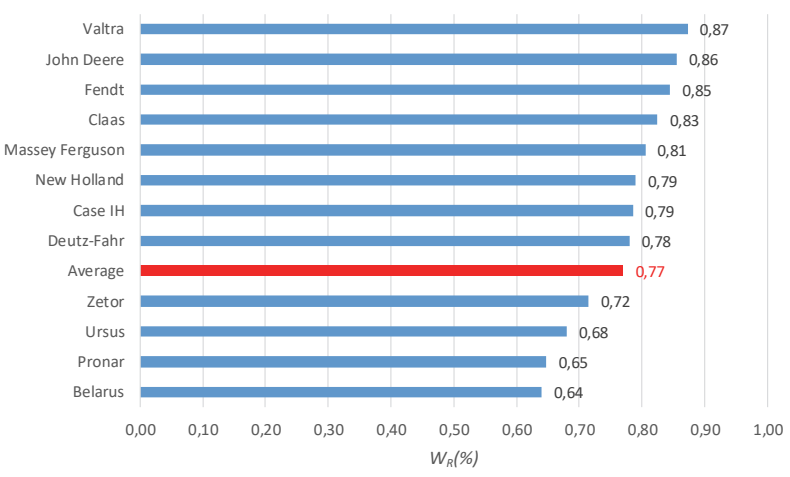

Figure 5 The first Polish ranking of the reliability of farm tractor brands based on users' opinions.

Polish farmers found Valtra tractors manufactured in Scandinavia to be the most reliable as their failure rate was the lowest (Fig. 6). 


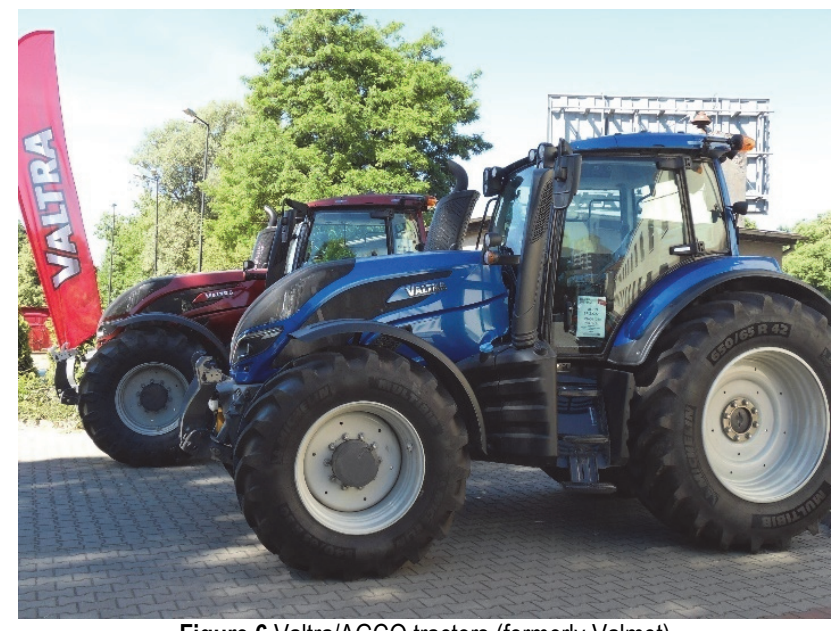

Figure 6 Valtra/AGCO tractors (formerly Valmet)

Among the 12 brands in the ranking, all individual indexes of the 11 ranking criteria were rated above average for Valtra tractors. As many as 10 individual criteria were rated best, and 6 dominated clearly-black in Fig. 7 and Fig. 8 .

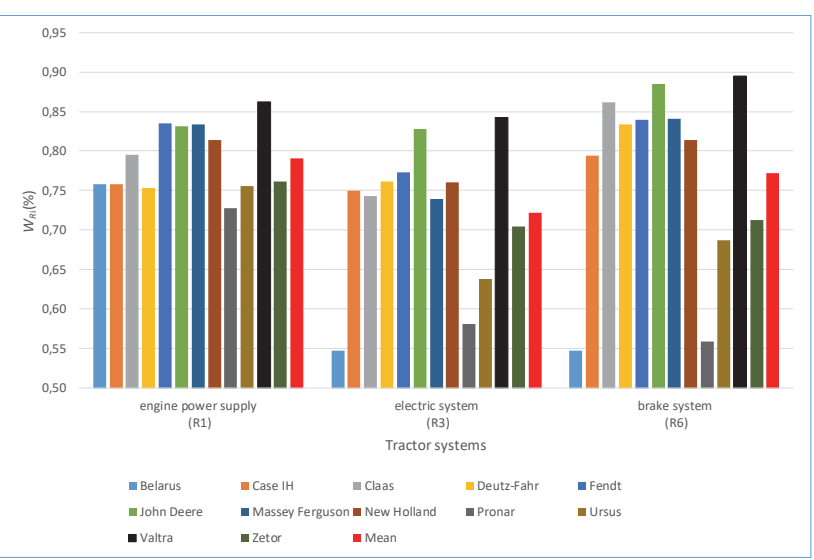

Figure 7 Individual reliability indexes $W_{R 1}(\%), W_{R 3}(\%)$ and $W_{R 6}(\%)$ of the 12 tractor brands and the average values.

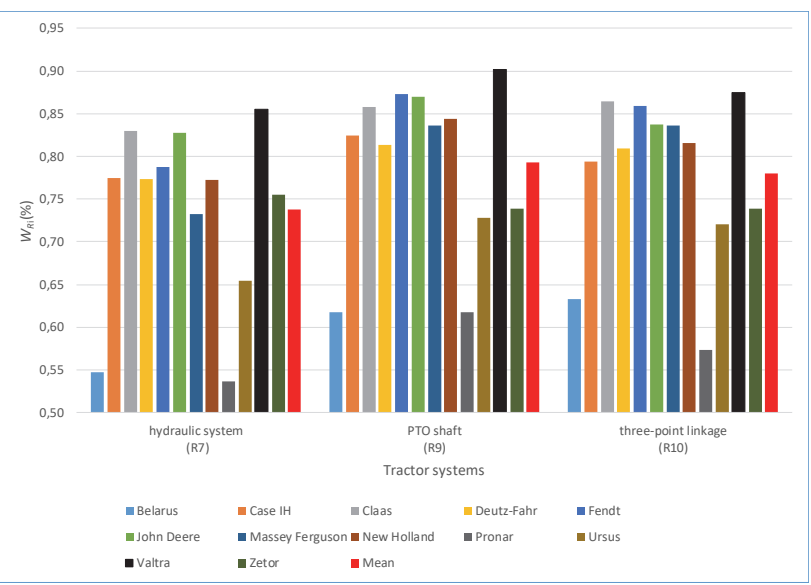

Figure 8 Individual reliability indexes $W_{R 7}(\%), W_{R 9}(\%)$ and $W_{R 11}(\%)$ of the 12 tractor brands and the average values.

The users were only critical about the failure rate in two criteria: $R_{5}$ - the gearbox and $R_{11}$ - connections.

Unfortunately, Polish, Czech and Russian tractors, which are the most common in Poland, were considered unreliable. Their reliability indexes were below average in each category. This ranking reflects the experts' opinions, which verified the proposed method empirically.

\section{SUMMARY AND CONCLUSIONS}

When using the classical theory of reliability the biggest problem is to obtain reliable and numerous data concerning failures of a technical facility over time. Even annual reliability/failure rankings published by the biggest automotive organisations such as DEKRA, TÜV, GTÜ from Germany, Warranty Direct from the UK or the JD Power marketing agency from the US are based on information from vehicle inspection stations. This is a very minimalistic approach, which strongly simplifies the reality. ADAC is slightly different. Their rankings are based on the number of calls for road assistance. This approach is in line with the classical theory of reliability, because when a car is immobilised, it does not fulfil its basic function. All the same, this event means failure.

However, even as large a population of data as a few million cars does not give identical final results. There are still different rankings published by 'Driver's Choice'-a Polish car portal, which has been operating only for a few years and which was the prototype for our IFOP portal.

For the time being there are no rankings of the reliability of a large population of agricultural machinery and vehicles used on farms. In Poland there are about 1.5 million farm tractors, 500000 field sprayers and 50000 orchard sprayers, 150000 combine harvesters, 80000 potato combine harvesters, and 28000 beet harvesters. However, neither manufacturers nor service stations want to share the knowledge that could be disadvantageous to the reputation of the brand. Hence the idea of the IFOP system, which is based on uncomplicated methodology of rating the reliability of agricultural equipment.

The IFOP project, which includes the media and substantive support of the top agrarPolska publishing house, is developing. Farmers welcomed the fact that it is independent and objective. Their involvement enabled the publication of the first rankings of the quality and reliability of farm tractors. The ranking encompassed vehicles manufactured in a period of 30 years and it showed a noticeable upward trend. It proved a globally good opinion of the durability and reliability of farm tractors, because the ranking was based on 1100 questionnaires sent in an online survey. Newer tractors were characterised by better quality and lower failure rate. This means that Polish farmers take care of their equipment and have it serviced regularly. They appreciate new systems improving the comfort of work and the safety of operation, equipment and the environment. Contrary to pessimistic forecasts, advanced IT, electronic, automation, sensory and actuation systems do not cause many failures, especially random ones. Therefore, the manufacturers of these tractors should be satisfied with their products.

The method cannot be validated because there are no similar reports. Therefore, at the moment, they can be considered as primary (output) values, which can be used as the basis for further quantification of the reliability of agricultural machinery.

Both knowledge and experience, especially one's own, gives grounds for creation of reliable rankings of reliability of technical facilities. There are more than 1.5 million farm tractors registered in Poland. Their users' subjective opinions were the basis for an objective report on the reliability of individual brands. A farm tractor is an 
agricultural machine that should be both functional and reliable. Only then can field work be done at optimal terms, regardless of the terrain and climate.

The reliability quantification method based on users' associations can be successfully used to make rankings of other agricultural machinery and vehicles. At the moment users can send their opinions to the IFOP system in English. In the near future other language options will also be available, i.e. German, Russian and Croatian.

\section{REFERENCES}

[1] d. Ayers, P. K. \&Venugopal V. K. (1987). Personal Computer Aided Design (PCAD) of Electro-Hydraulic Control Systems. Appl. Eng. in Agric., 3(2), 241-246. https://doi.org/10.13031/2013.26682

[2] Kline, D. E., Bender, D. A., \& McCarl, B. A. (1989). FINDS: Farm-Level Intelligent Decision Support System. Appl. Eng. in Agric., 5(2), 273-282. https://doi.org/10.13031/2013.26513

[3] Durczak, K., Ekielski, A., \& Żelaziński, T. (2018). Calculation of the reliability function from actual failures resulting from the operation of one make of farm tractors. $J$. of Resear. andApplic. in Agric. Eng., 63(1), 18-22, ISSN 1642-686X.

[4] Durczak, K. \& Jurek, P. (2017). Safety and ergonomics as important criteria of quality of agricultural machinery. $J$. of Resear. andApplic. in Agric. Eng., 62(2), 27-31, ISSN 1642$686 \mathrm{X}$

[5] Durczak, K., Czechlowski, M., Ekielski, A., \& Jurek, P. (2018). Farm Tractor Reliability Quantification with the DPO Indicator. Eng. Studies, 3(2), 417-436. Print ISSN: 1937-8629. Online ISSN: 1940-8374.

[6] Jiang, J., Roussas, G. G., \& Samaniego, F. J. (2012). Nonparametric Statistical Methods and Related Topics. World Scientific Publishing Company. https://doi.org/10.1142/8258

[7] Benbow, D. W. \& Broome, H. W. (2013). The Certified Reliability Engineer Handbook, Second Edition. $A S Q$ Quality Press, Milwaukee, Wisconsin.

[8] Keller-McNulty, S. (2005). Modern Statistical And Mathematical Methods in Reliability. World Scientific Publishing Company, ISBN: 981-256-356-3.

[9] Smith, D. J. (2011). Reliability maintainability and risk. Practical Methods for Engineers. Butterworth-Heinemann.

[10] Zio, E. (2007). Introduction to the Basics of Reliability and Risk Analysis. World Scientific Publishing Company. https://doi.org/10.1142/6442

[11] Durczak, K., Jurek, P., Beba, J., Ekielski, A., \& Żelaziński, T. (2018). A Multistate Model of Reliability of Farming Machinery. BIO Web Conf. - 2018, 10(02005), Contemporary Research Trends in Agricultural Engineering, Kraków, Poland, September 25-27, 2017. https://doi.org/10.1051/bioconf/20181002005

[12] Cochrane, J. L. \& Zeleny, M. (1973). Multiple Criteria Decision Making. University of South Carolina Press.

[13] Deb, K. (2001). Multi-Objective Optimization using Evolutionary Algorithms. John Wiley \& Sons, Inc. New York, NY, USA, ISBN:047187339X.

[14] Fandel, G., Spronk, J., \& Matarazzo, B. (1985). Multiple Criteria Decision Methods and Applications. SpringerVerlag, Berlin. https://doi.org/10.1007/978-3-642-70583-0

[15] Greco, S., Ehrgott, M., \& Figueira, J. R. (2016). Multiple Criteria Decision Analysis. State of the Art Surveys. International Series in Operations Research \& Management Science \#232. Kluwer Academic Publishers Boston/Dordrecht/London. https://doi.org/10.1007/978-1-4939-3094-4
[16] Burke, E. K. \& Kendal, G. (2013). Search Methodologies: Introductory Tutorials in Optimization and Decision Support Techniques. Springer Publishing Comp., Incorporated ISBN:14614693929781461469391.

[17] Eiselt, H. A. \& Sandblom, C. L. (2012). Operations Research: A Model-Based Approach. Springer; 2nd ed. 2013 edition, ISBN-10: 3642310532 https://doi.org/10.1007/978-3-642-31054-6

[18] Saaty, T. L. (1980). The Analytic Hierarchy Process: Planning, Priority Setting, Resource Allocation. MacGrawHill.

[19] Miller, G. A. (1956). The magical number seven, plus or minus two: Some limits on our capacity for processing information. Psychol. Rev.,63(2), 81-97. https://doi.org/10.1037/h0043158

[20] Ammann, H. (2007). Maschinenkosten 2008. Kostenansätze Gebäudeteile und mechanische Einrichtungen. ARTBerichte, 688.

[21] Gazzarin, C. (2018). Maschinenkosten 2018. Agroscope Transfer, 243.

Contact information

Karol DURCZAK, Assoc. Prof. PULS

(Corresponding author)

Poznań University of Life Sciences

Institute of Biosystems Engineering,

UI. WojskaPolskiego 50, 60-627 Poznań, Poland

E-mail: karol.druczak@up.poznan.pl 